Correction

\title{
Correction: Evaluating prognosis by CK7 differentiating renal cell carcinomas from oncocytomas can be used as a promising tool for optimizing diagnosis strategies
}

\author{
Fuling Ma ${ }^{1, *}$, Liang Dai ${ }^{1, *}$, Zhun Wang ${ }^{1, *}$, Liqun Zhou ${ }^{2}$, Yuanjie Niu ${ }^{1}$ and Ning Jiang ${ }^{1}$ \\ ${ }^{1}$ Department of Urology, 2nd Hospital of Tianjin Medical University, Tianjin Institute of Urology, Tianjin 300211, China \\ 2 Department of Urology, Peking University First Hospital, The Institute of Urology, Peking University, Beijing 100034, China \\ * These authors have contributed equally to this work
}

Published: June 26, 2018

Copyright: Ma et al. This is an open-access article distributed under the terms of the Creative Commons Attribution License 3.0 (CC BY 3.0), which permits unrestricted use, distribution, and reproduction in any medium, provided the original author and source are credited.

This article has been corrected: The complete funding information is given below:

\section{FUNDING}

The project was supported by a research grant of National Basic Research Program of China (973 Program, 2012CB518304). and the Science Foundation of Tianjin (No.: 11JCZDJC19700, 16JCZDJC34400) and 09ZCZDSF04300, 14KG135, 20140117 and the National Natural Science Foundation of China Grant numbers: 2012DFG32220 and 81572538, 81472682. Ph.D Programs Foundation of Ministry of Education of China 20131202110008.

Original article: Oncotarget. 2016; 7:46528-46535. https://doi.org/10.18632/oncotarget.10225 